\title{
LÜSEBRINK, Hans-Jürgen, REICHARDT, Rolf, Kulturtransfer im Epochenumbruch Frankreich Deutschland 1770 bis 1815
}

Anne Saada

\section{OpenEdition}

Édition électronique

URL : http://journals.openedition.org/ifha/1278

DOI : $10.4000 /$ ifha. 1278

ISSN : 2198-8943

Éditeur

IFRA - Institut franco-allemand (sciences historiques et sociales)

Référence électronique

Anne Saada, «LÜSEBRINK, Hans-Jürgen, REICHARDT, Rolf, Kulturtransfer im Epochenumbruch Frankreich Deutschland 1770 bis 1815 », Revue de I'IFHA [En ligne], Date de recension, mis en ligne le 01 janvier 2001, consulté le 22 septembre 2020. URL : http://journals.openedition.org/ifha/1278 ; DOI : https://doi.org/10.4000/ifha. 1278

Ce document a été généré automatiquement le 22 septembre 2020.

(CIFHA 


\section{LÜSEBRINK, Hans-Jürgen, REICHARDT, Rolf, Kulturtransfer im Epochenumbruch Frankreich Deutschland 1770 bis 1815}

Anne Saada

1 Ces deux volumes, issus d'un colloque, constituent la somme la plus importante des travaux sur les transferts culturels franco-allemands entre 1770 et 1815 : ils réunissent 27 contributions, qui se divisent en cinq groupes. Une première série d'articles porte sur les théories des transferts culturels. H.-J.L., R.R. et R. NOHR y exposent les résultats d'une ample analyse sur le genre et l'évolution des traductions allemandes d'ouvrages français (au total, 16000 traductions) entre 1770 et 1815. M. WERNER traite d'un thème particulièrement difficile, à savoir les dissymétries et les constructions de modèles symétriques dans les recherches sur les transferts culturels : ne peut-on comparer que des catégories ou des phénomènes identiques ? B. SPILLNER s'intéresse à la forme par laquelle passent les transferts culturels, c'est-à-dire la langue. Il introduit aux méthodes utilisées dans la comparaison des langues et des traductions. C. ULBRICH propose une réflexion sur les processus de transferts dans les espaces frontières.

2 La deuxième série d'articles, qui a pour objet les processus d'information et de perception, rassemble des études de cas. Les sources principales utilisées par les cinq auteurs ont été les journaux, médias par excellence des transferts culturels. K. ANGELIKE, M. BEERMANN et R. NOHR étudient de façon extrêmement précise et minutieuse les journaux francophones dans la région du Rhin. W. GRELLING et $\mathrm{M}$. MIDDELL traitent des nouvelles sur la France dans les journaux publiés en Saxe et en Thuringe pendant la Révolution; M. WAGNER signe une contribution sur la réception dans la presse du procès de Louis XVI en 1793. L'article de W.H. STEIN ne s'attache pas à la presse, mais à la langue employée par l'administration dans les départements du Rhin entre 1798 et 1814 , c'est-à-dire le français. 
3 La troisième série d'articles a pour thème les porteurs et les institutions qui organisent les échanges culturels. M. ESPAGNE, après des réflexions théoriques sur la thématique des transferts, dresse une sorte de typologie des principaux porteurs de ces échanges culturels : artistes, artisans et négociants ; il attire également l'attention sur le rôle original et inattendu joué par les ennemis de la France dans les processus de transferts culturels. Les contributions suivantes portent sur les traducteurs et les éditeurs : G. ROCHE présente le cas du traducteur Ludwig Ferdinand Huber et M. LEHMSTEDT celui du libraire Peter Philipp Wolf à Leipzig ; J. FREEDMAN analyse les rapports entre la Société Typographique de Neuchâtel et le marché du livre allemand, et R. NOHR dessine une carte extrêmement utile des principaux lieux dans lesquels étaient implantés les éditeurs spécialisés dans le domaine des traductions. L'article qui ferme cette section (R. NOHR, E. PAPPACEK et A. VETTER) porte sur les recensions de ces ouvrages français traduits en allemand.

4 Le second volume s'ouvre par une série d'études sur les formes et les processus de traduction. Tour à tour sont analysées la traduction et la transformation du genre encyclopédique (C. DONATO), la réception de la comédie (M. GRIMBERG), les traductions d'opéras (H. SCHNEIDER) ainsi que la structure et la réception des traductions de Voltaire et de Raynal (H.-J. LÜSEBRINK). C. DANELZIK-BRÜGGEMANN étudie dans le domaine de l'image - illustrations, gravures - l'influence du modèle français en Allemagne.

5 La dernière section est consacrée au transfert de concepts et de symboles. L'article de A. KEILHAUER aborde le thème à travers l'étude des dictionnaires bilingues. Les quatre autres contributions s'attachent à l'analyse de termes clés : " démocratie » (F.J. MEIßNER), " Nation » (H.-J. LÜSEBRINK, P. DEN BOER) et " Révolution » (R. REICHARDT).

6 Les contributions rassemblées dans ces deux volumes se caractérisent par leur sérieux et leur richesse. Loin de mettre un terme à la thématique des transferts culturels, elles incitent, en proposant de nombreux axes de réflexions, à poursuivre sur des bases solides les recherches entreprises dans ce domaine. 